\title{
Penerapan CFTT untuk Pengujian Aplikasi Web-Based Android Analysis Tools (WAAT) Dengan Federated Testing
}

\author{
Yasir Muin*1, Yudi Prayudi ${ }^{2}$, Fietyata Yudha ${ }^{3}$ \\ ${ }^{1,2}$ Universitas Islam Indonesia; Yogyakarta, (0274) 895287 \\ ${ }^{3}$ Forensika Digital, Magister Informatika, FTI, Yogyakarta \\ e-mail:*119917018@students.uii.ac.id, 2prayudi@uii.ac.id, ${ }^{3}$ yudha@uii.ac.id
}

\begin{abstract}
Abstrak
Perkembangan smartphone membuat aktivitas manusia lebih muda, dengan fitur-fitur yang diberikan, perkembangan tersebut tidak menutup kemungkinan dengan kecanggihan fitur smartphone dimanfaatkan sebagai media komunikasi untuk mendukung bentuk aksi kejahatan. Proses investigasi forensik dalam penanganan barang bukti elektronik pada smartphone menjadi sebuah tantangan bagi ahli forensik karena perkembangan smartphone yang terus berkembang. permasalahan yang dihadapi oleh ahli forensik adalah sulit menentukan tools forensik yang harus digunakan dalam penanganan barang bukti karena beberapa aplikasi yang dikembangan belum diuji dengan standar forensik. untuk itu dalam penelitian ini akan dilakukan pengujian aplikasi web based android analysis tools berdasarkan standar computer forensics tools testing menggunakan aplikasi federated testing. pengujian ini dilakukan untuk mengetahui kelayakan aplikasi web based dengan melakukan evaluasi data antara hasil pengujian web based dan hasil pengujian federated testing. dari hasil evaluasi tersebut didapatkan bahwa aplikasi web based masih lebih rendah dibandingkan dengan federated testing karena pada aplikasi web based hanya mampu menghasilkan empat variabel data yang sama dengan laporan federated testing, sedangkan data lainnya belum di support oleh aplikasi tersebut, sehingga dapat dapat disimpulkan bahwa aplikasi web based android analysis tools ini belum memenuhi syarat standarisasi cftt.
\end{abstract}

Kata kunci-Mobile forensik investigasi, Web based android analysis tools, CFTT, Federated testing

\begin{abstract}
The evolutionary of smartphones and their technology simplify human activitie, with the features provided, this development does not rule out the sophistication of smartphone features being used as a medium of communication to support forms of crime. The process of forensic investigations in handling electronic evidence on smartphones is a challenge for forensic experts because of the ever-growing development of smartphones. The problem faced by forensic experts is that it is difficult to determine the forensic tools that should be used in handling evidence because several applications developed have not been tested with forensic standards. For this reason, this research will conduct web application testing based on android analysis tools based on standard computer forensics testing tools using the federated testing application. This test is conducted to determine the feasibility of a web-based application by evaluating the data between the results of the web-based test and the results of the federated testing. From the results of the evaluation, it was found that the web-based application was still lower than the federated testing because the web-based application was only able to produce the same four data variables as the federated testing report, while other data had not been
\end{abstract}


supported by the application, so it could be concluded that the application This web-based android analysis tool does not meet standardization CFTT requirements.

Keywords - Mobile forensics investigation, Web based android analysis tools, CFTT, Federated testing

\section{PENDAHULUAN}

Perangkat bergerak mengalami perkembangan yang sangat pesat seiring dengan perkembangan teknologi [1], dengan berbagai fitur dan kemampuan yang dimiliki oleh perangkat ponsel gawai, mengakibatkan lonjakan signifikan pertumbuhan penggunaan perangkat ponsel pada beberapa tahun terakhir [2]. Meningkatnya penggunaan ponsel tidak menutup kemungkinan kecanggihan fitur ponsel dimanfaatkan sebagai media komunikasi untuk mendukung bentuk aksi kejahatan [3], pada tahun 2020 newzoo telah mencatat kasus kejahatan pada perangkat ponsel di Indonesia sebanyak 58,6\% dengan jenis serangan yang variatif [4]. kejahatan memberikan tantangan tersendiri bagaimana mengekstrak dan menganalisis data secara efektif pada perangkat ponsel android untuk tujuan forensik [5].

Proses investigasi penangan barang bukti digital menjadi sebuah tantangan bagi ahli forensik karena perkembangan fitur-fitur pada ponsel yang selalu berkembang setiap tahunnya. Banyak Perkakas mobile forensik yang mempunyai kelebihan dan kekurangan serta fitur - fitur yang berbeda satu dengan yang lainnya memberikan pengaruh terhadap hasil yang didapatkan, untuk perlu adanya sebuah standarisasi yang mengatur tentang data apa saja yang harus dihasilkan oleh setiap aplikasi mobile forensik berdasarkan standar forensik. dan bagaimana aplikasi mobile forensik itu diuji berdasarkan standar tersebut sehingga hasil yang didapatkan bisa digunakan oleh laboratorium atau ahli forensik digital.

Computer forensics tools testing (CFTT) adalah salah satu standarisasi national institute of standard and technology (NIST). merupakan sebuah metode pengujian perangkat lunak forensik digital yang dikembangkan secara umum untuk menguji aplikasi berdasarkan fungsionalitas yang didukungnya [6]. salah satu aplikasi cftt dibuat untuk menguji menguji aplikasi mobile forensik adalah federated testing. aplikasi ini merupakan pengembangan dari cftt yang diperuntukan bagi para ahli atau laboratorium forensik untuk menguji aplikasi yang dikembangakan. pengujian dilakukan untuk mengetahui kelayakan sebuah aplikasi mobile forensik dalam menghasilkan data sudah memenuhi standar yang diterapkan

Aplikasi web-based android analysis tools (WAAT) merupakan pengembangan aplikasi yang dikembangkan oleh salah satu mahasiswa universitas islam indonesia untuk memenuhi tugas akhirnya. aplikasi WAAT ini merupakan aplikasi forensik digital untuk analisis mobile forensik, namun pada aplikasi WAAT ini belum diuji secara forensik sehingga belum dapat mengetahui kemampuan dalam menganalisa kasus mobile forensik. Untuk itu dalam penelitian bertujuan untuk melakukan pengujian aplikasi waat untuk mengetahui kelayakan aplikasi berdasarkan standar CFTT. Pengujian standarisasi forensik didasarkan pada laporan pengujian aplikasi federated testing yang mana laporan tersebut dijadikan sebagai standar untuk memvalidasi atau mengukur aplikasi waat untuk mengetahui seberapa banyak data yang di support dan tidak di support oleh aplikasi WAAT.

\section{KAJIAN LITERATUR}

Pada tahun 2019 [7] membahas keadaan pengujian alat forensik digital saat ini di 2018 bersama dengan kesulitan aplikasi pengujian yang cukup untuk digunakan dalam disiplin ini.

Muin, et., al [Penerapan CFTT untuk Pengujian Aplikasi Web-Based Android Analysis Tools (WAAT) Dengan Federated Testing] 
Hasil selanjutnya pun investigasi menggunakan alat tersebut harus dapat diandalkan dan dapat diulang sambil mendukung pendirian fakta, memungkinkan proses peradilan pidana kemampuan untuk mencerna setiap temuan selama proses menentukan rasa bersalah atau tidak bersalah. Kesalahan yang ada pada setiap tahap pemeriksaan dapat merusak keseluruhan investigasi, mengkompromikan hasil yang berpotensi sebagai bukti.

Pada tahun 2014 [8] dalam proyek CFTT telah menulis persyaratan alat, rencana pengujian dan pengujian alat forensik selama 10 tahun terakhir. Secara umum, hasilnya benar untuk kritis fungsi alat diminta untuk dilakukan. Beberapa kesalahan serius telah ditemukan, dan vendor alat mampu memperbaiki masalah dengan cepat. Sebagian besar masalah hanyalah perilaku unik yang bisa terjadi dihindari jika praktisi menyadarinya. Selama beberapa tahun ke depan CFTT akan berkembang menguji area fungsional lainnya seperti string mencari, perolehan memori langsung, alat triase dan ekstraksi email. Area lain akan coba dibuat metodologi pengujian $C F T$ tersedia untuk forensic laboratorium dalam bentuk yang mudah bagi laboratorium untuk menguji alat forensik dengan cara yang umum dan untuk memfasilitasi berbagi hasil tes dan bahan tes.

Pada tahun 2009 [9] menggunakan pendekatan pengujian untuk membandingkan kinerja alat forensik digital tanpa menggunakan peralatan canggih atau hanya menghabiskan banyak waktu. Hasil pengujian telah membuktikan validitas dan efektivitas metodologi. Selain itu, metode yang digunakan lebih efisien daripada yang lainnya. Metodologi yang digunakan sepenuhnya otomatis yang terkomputerisasi dapat dikembangkan untuk di masa depan. Prosedur yang dilakukan khusus untuk pengujian alat forensik digital karena memenuhi persyaratan keadilan dan kebutaan, dan dapat dijalankan, tanpa jeda, selama diperlukan untuk mencapai hasil yang akurat.

Pada tahun 2019 [10] dalam penelitiannya mengambil bagian dalam pengembangan dan evaluasi kurikulum pada sebuah Universitas dengan memasukkan National Institute Standar dan Teknologi (NIST) dengan menetapkan CFTT sebagai standar untuk forensic digital. Tujuan proyek CFTT adalah untuk membangun metodologi untuk menguji perangkat lunak forensik komputer dengan pengembangan dari spesifikasi alat umum, prosedur pengujian, kriteria pengujian, pengujian set, dan uji perangkat keras

\section{METODE PENELITIAN}

Proses penelitian ini diawali dengan identifikasi kebutuhan, tinjauan pustaka, skenario kasus, akuisisi barang bukti, pengujian aplikasi, evaluasi dan hasil pengujian seperti pada gambar 1. 


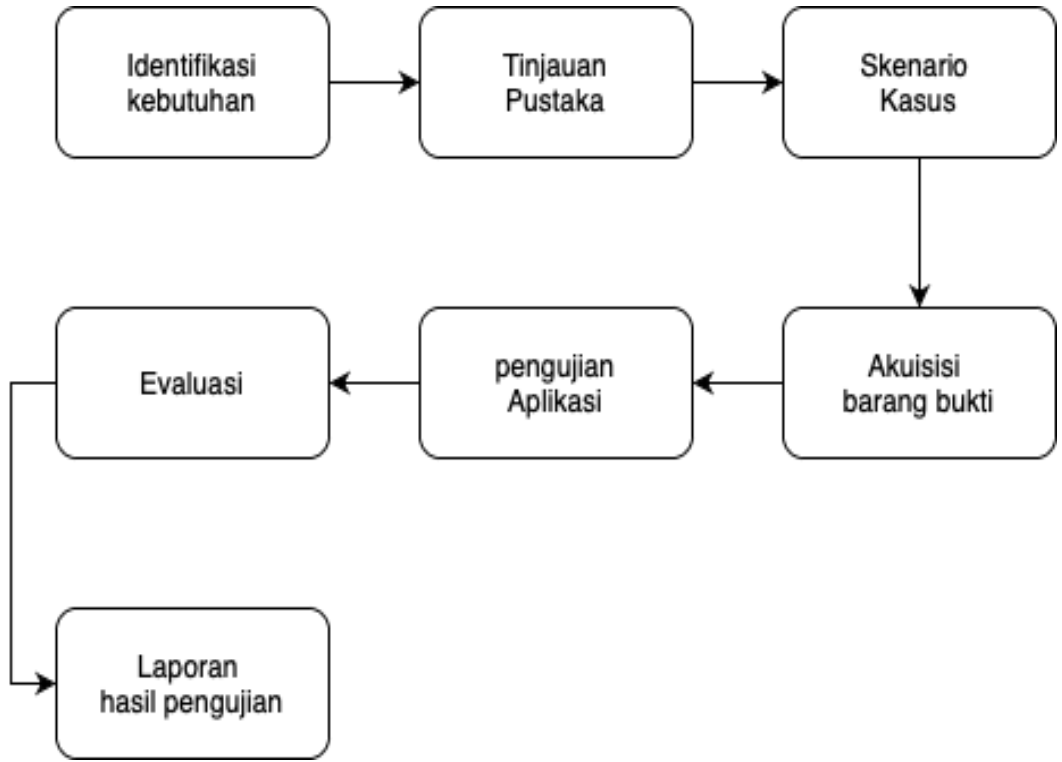

Gambar 1. Alur Penelitian.

1. Identifikasi Kebutuhan

Proses identifikasi dilakukan untuk menentukan kebutuhan apa saja yang diperlukan dalam pengujian aplikasi WAAT.

2. Tinjauan Pustaka

Tinjauan pustaka merupakan tahapan untuk mengkaji dan mempelajari berbagai sumber literatur dan teori-teori pendukung terkait penelitian baik itu dari jurnal, paper, artikel, buku-buku, website dan sumber lain yang berkaitan dengan forensik tools testing dan federated testing.

3. Skenario Kasus

Penelitian ini dilakukan tiga skenario pengujian aplikasi WAAT, skenario tersebut terdiri dari akuisisi barang bukti, pengujian aplikasi, dan evaluasi. Untuk lebih jelasnya skenario akan dijelaskan pada tabel 1 .

Tabel 1. Skenario Kasus

\begin{tabular}{|l|l|}
\hline \multicolumn{1}{|c|}{ Skenario } & \multicolumn{1}{c|}{ Keterangan } \\
\hline 1. Akuisisi & $\begin{array}{l}\text { Skenario yang menjelskan tentang proses ekstraksi data dari } \\
\text { perangkat ponsel menggunakan teknik forensik digital. } \\
\text { Proses akuisisi dilakukan untuk membuat sebuah data image } \\
\text { yang bisa digunakan dalam proses pengujian aplikasi. }\end{array}$ \\
\hline 2. Pengujian Aplikasi & $\begin{array}{l}\text { Skenario ini menjelaskan tentang pengujian aplikasi WAAT } \\
\text { yang diuji dengan federated testing berdasarkan standar cftt. } \\
\text { proses pengujian aplikasi WAAT ini dimulai dengan } \\
\text { melakukan mounting dari file image yang suda diakuisisi } \\
\text { sebelumnya, selanjutnya mengekseskusi file mounting ke } \\
\text { aplikasi WAAT dengan memanggil direktori mount-nya. }\end{array}$ \\
\hline 3. Evaluasi & $\begin{array}{l}\text { Skenario ini dilakukan untuk mengevaluasi hasil pengujian } \\
\text { aplikasi WAAT, dengan hasil federated testing untuk } \\
\text { mengetahui hasil yang didaptkan dari aplikasi WAAT } \\
\text { berdasarkan standar cftt. }\end{array}$ \\
\hline
\end{tabular}


4. Pengujian Aplikasi

Pengujian aplikasi dilakukan menjadi dua tahap yaitu pengujian WAAT dan pengujian federated testing yang dilakukan secara tersendiri. Pengujian digunakan untuk menguji aplikasi WAAT dengan federated testing berdasarkan standar cftt.

pengujian aplikasi WAAT dilakukan berdasarkan alur pengujian sesuai dengan gambar 2 .

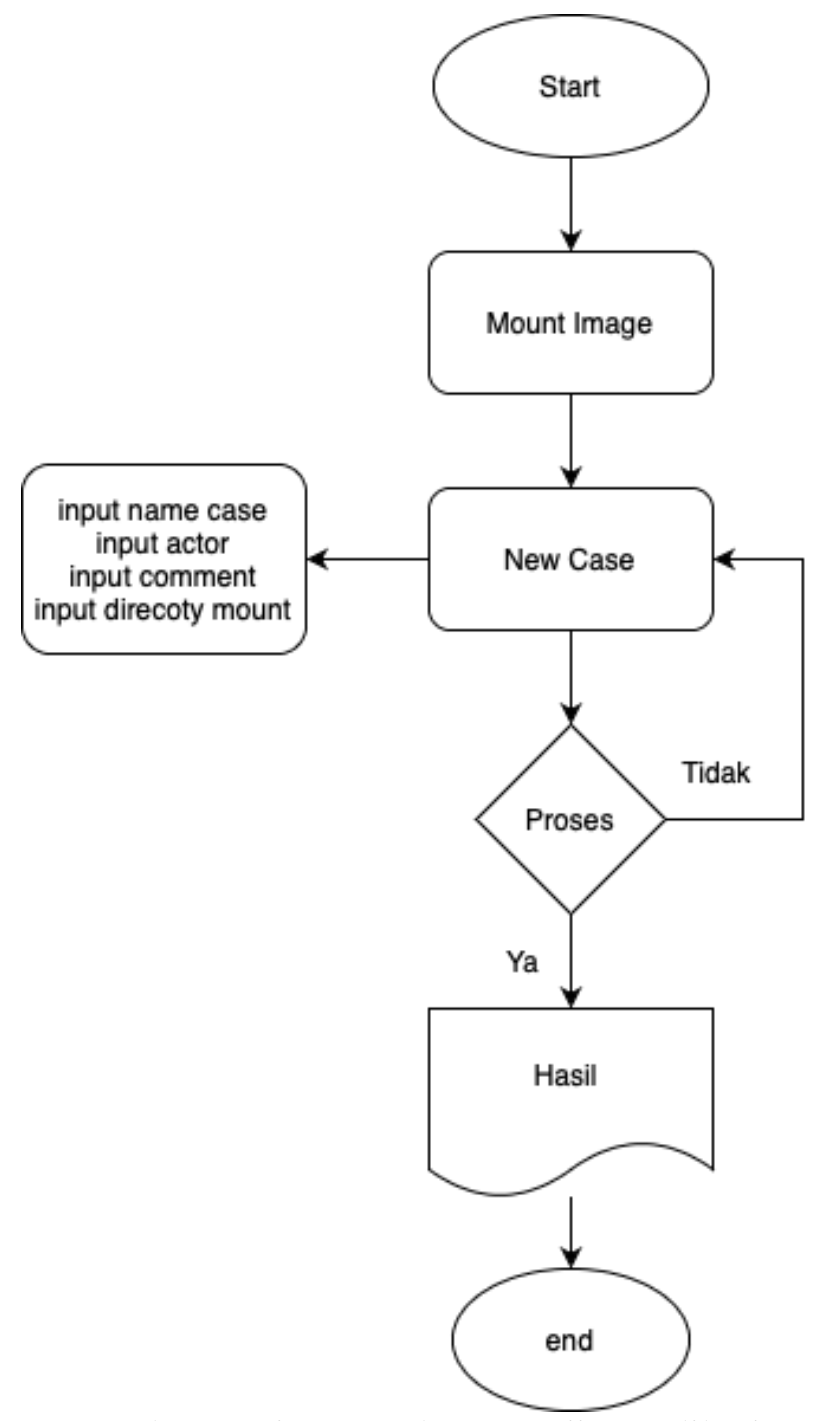

Gambar 2. Diagram Alur Pengujian Aplikasi WAAT.

Pengujian aplikasi federated testing merupakan sebuah program cftt yang menyediakan fasilitas untuk menguji aplikasi web based, pengujian ini dilakukan untuk mengetahui mengetahui kemampuan aplikasi secara fungsional berdasarkan standar cftt.

5. Evaluasi

skenario merupakan proses evaluasi dari kedua aplikasi WAAT, evaluasi dilakukan untuk mengetahui kemampuan aplikasi web based terhadap hasil yang didapatkan sesuai dengan laporan pada federated testing sesuai dengan standar cftt. 


\section{HASIL DAN PEMBAHASAN}

Berdasarkan metodologi yang suda dibuat berdasarkan skenario yang dibangun sebagai gambaran dari proses pengujian aplikasi, maka selanjutnya akan melakukan pengujian aplikasi WAAT yang diuji berdasarkan standar cftt dengan federated testing. Pengujian dijelaskan secara bertahap, dimulai dari tahap akuisisi, pengujian aplikasi WAAT dan hasil laporan hasil pengujian.

Akuisisi Barang bukti merupakan proses ekstraksi data dari perangkat ponsel untuk digunakan dalam proses pengujian aplikasi, proses ekstraksi ini menggunakan perkakas adb, busybox, dan netcut. Dapat dilihat perintah untuk mengekstrak data seperti yang ditunjukan pada gambar 3.
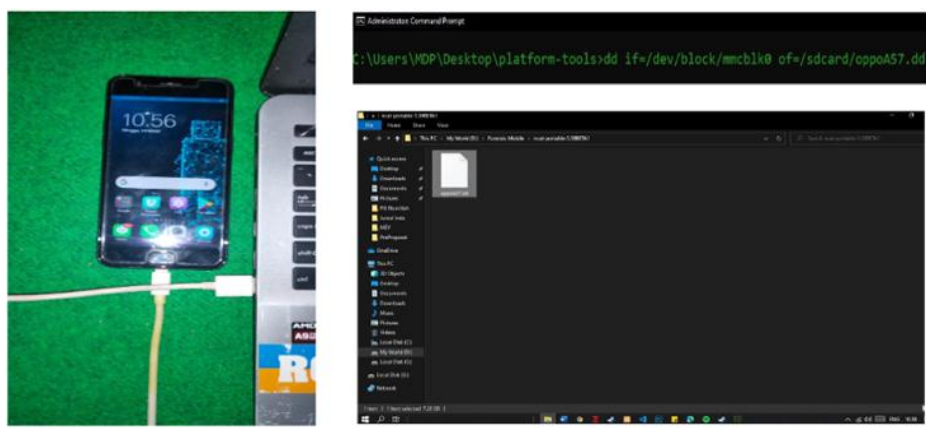

Gambar 3. Barang Bukti Didital pada Ponsel

Pengujian aplikasi WAAT merupakan sebuah tahap yang menjelaskan proses pengujian aplikasi. Proses tersebut dijelaskan pada gambar 4.

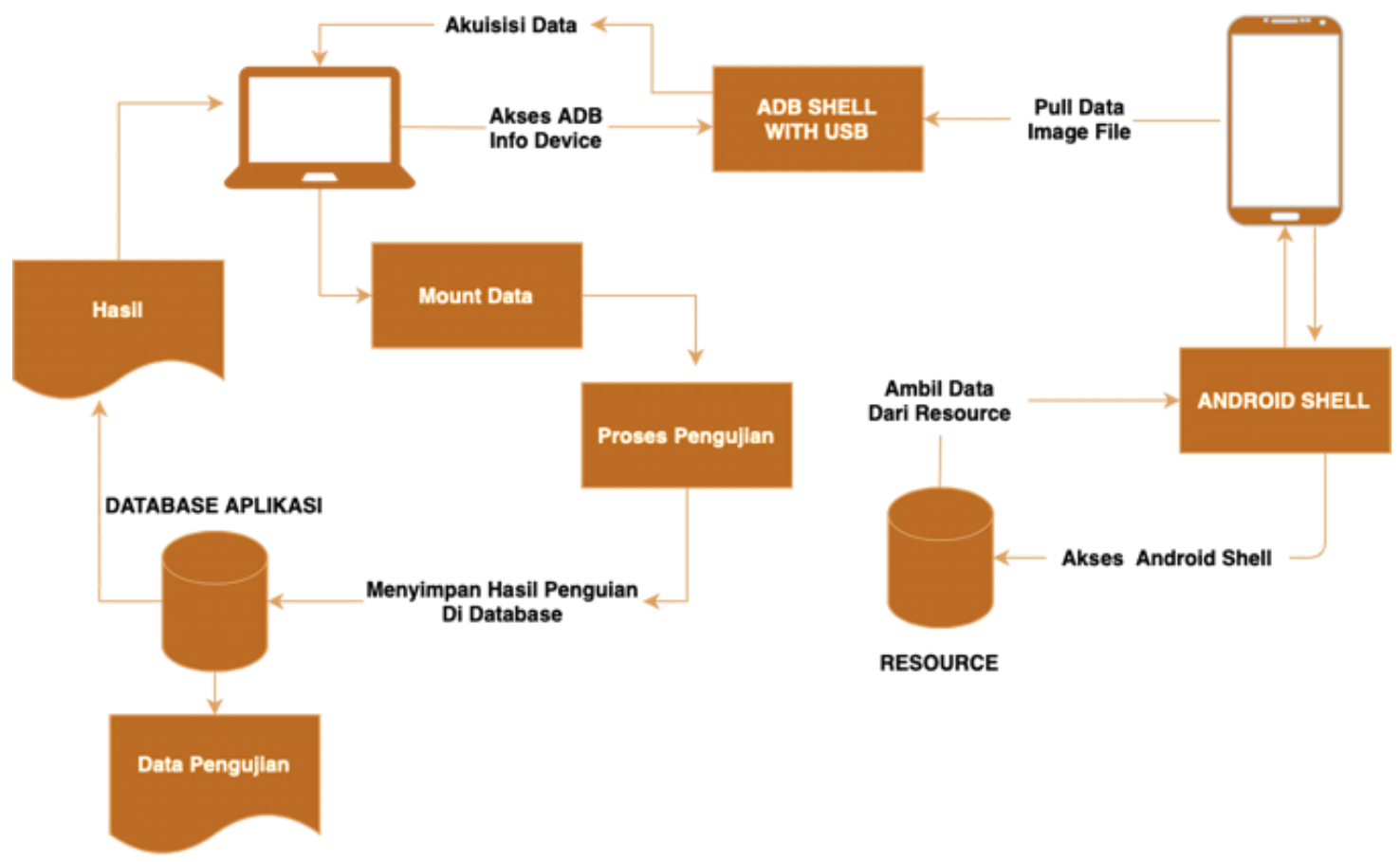

Gambar 4. Workflow Web Based Android Analysis Tools.

Muin, et., al [Penerapan CFTT untuk Pengujian Aplikasi Web-Based Android Analysis Tools (WAAT) Dengan Federated Testing] 
Gambar 4.2 merupakan sebuah skema atau visualisasi yang menggambarkan tentang tahapan pengujian aplikasi, yang dimulai dari proses ekstraksi data dari ponsel, kemudian data tersebut dilakukan mounting untuk bisa di eksekusi oleh aplikasi, setelah data berhasil $d i$ mounting maka proses berikutnya adalah melakukan pengujian aplikasi dengan menginput perintah yang diminta aplikasi. Aplikasi kemudian memproses data tersebut dan menampilkan hasil pengujian ke halaman utama aplikasi seperti yang ditampilkan pada tabel 2.

Tabel 2. Hasil Pengujian Aplikasi Web Based Android Analysis Tools.

\begin{tabular}{|c|c|c|c|}
\hline \multicolumn{2}{|c|}{ Data Objek } & Status & Keterangan \\
\hline \multirow{2}{*}{$\begin{array}{l}\text { Data } \\
\text { Contact }\end{array}$} & Contact telphon & As Excepted & $\begin{array}{l}\text { Data yang dihasilkan sesuai dengan } \\
\text { harapan }\end{array}$ \\
\hline & Contact whatsapp & partial & Hanya sebagian data yang di hasilkan \\
\hline \multirow{3}{*}{ Call Log } & Incoming & As excepted & \multirow{3}{*}{$\begin{array}{l}\text { Data yang dihasilkan sesuai dengan } \\
\text { harapan }\end{array}$} \\
\hline & Outgoung & As excepted & \\
\hline & Reject & As excepted & \\
\hline \multirow{2}{*}{$\begin{array}{l}\text { Social } \\
\text { Media }\end{array}$} & Facebook massage & As excepted & $\begin{array}{l}\text { Data yang dihasilkan sesuai dengan } \\
\text { harapan }\end{array}$ \\
\hline & Whatsapp massage & Partial & Hanya sebagian data yang di hasilkan \\
\hline \multirow{3}{*}{$\begin{array}{l}\text { Network } \\
\text { connect }\end{array}$} & Concet to AP & As excepted & \multirow{3}{*}{ Hanya sebagian data yang di hasilkan } \\
\hline & Device info & As excepted & \\
\hline & Wifi tethering & As excepted & \\
\hline \multirow{3}{*}{ Application } & availinle application & As excepted & \multirow{3}{*}{ Hanya sebagian data yang di hasilkan } \\
\hline & Application-install & As excepted & \\
\hline & Platform version & As excepted & \\
\hline Account & Youtube account & As excepted & Hanya sebagian data yang di hasilkan \\
\hline \multirow[t]{3}{*}{ Screen lock } & Password quality & N/A & \multirow{3}{*}{ Tidak Suport } \\
\hline & Numerik digit & $N / A$ & \\
\hline & symbol & N/A & \\
\hline
\end{tabular}

Pengujian aplikasi federated testing dilakukan untuk menguji aplikasi WAAT berdasarkan standar cftt. proses pengujian dilakukan berdasarkan alur kerja yang ada pada gambar 5.

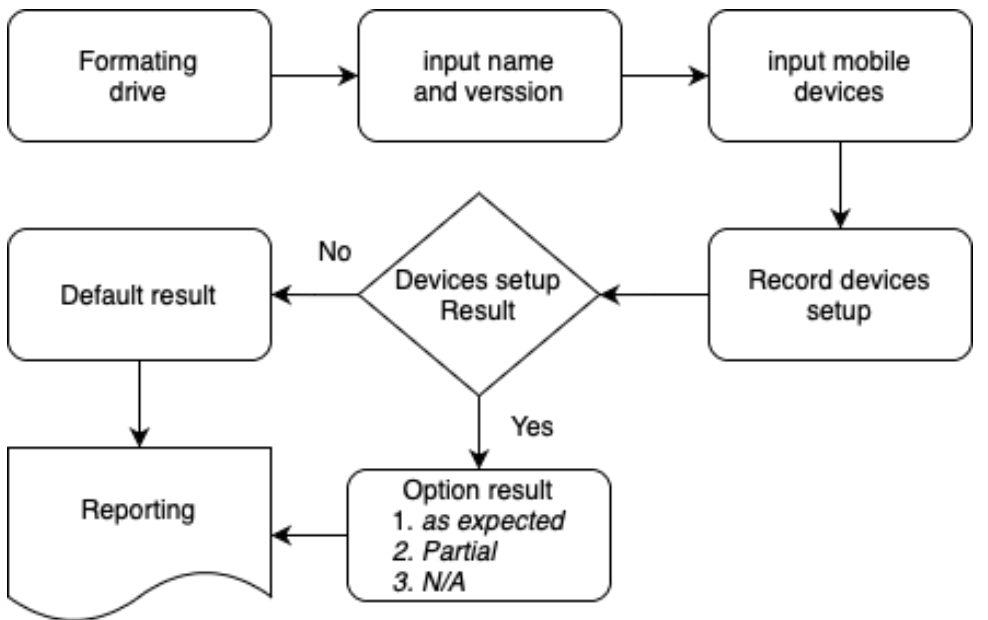

Gambar 5. Workflow federated testing. 
Gambar 5, merupakan tahapan pengujian aplikasi federated testing, output dari pengujian ini berupa sebuah laporan yang dipakai sebagai standar pengujian aplikasi WAAT. Proses pengujian federated testing menghasilkan data sebagai berikut, seperti yang ditampilkan pada tabel 3 .

Tabel 3. Hasil Pengujian Aplikasi Federated Testing.

\begin{tabular}{|c|c|c|}
\hline \multicolumn{2}{|c|}{ Data Objek } & Status \\
\hline \multirow{2}{*}{ Contact/ address entitas } & Reguler langth & populated \\
\hline & Blank name & populated \\
\hline \multirow{3}{*}{ Call Log } & Group contact & populated \\
\hline & Outgoung & populated \\
\hline & Missed & populated \\
\hline \multirow{2}{*}{ Social Media } & Facebook massage & populated \\
\hline & Twitter & populated \\
\hline \multirow{3}{*}{ Data File } & Instagram & populated \\
\hline & Audio & populated \\
\hline & Video & populated \\
\hline \multirow{3}{*}{ SMS Massage } & Document & populated \\
\hline & incoming & populated \\
\hline & Outgoing & populated \\
\hline \multirow{2}{*}{ MMS Masage } & Incoming audio, video & populated \\
\hline & Outgoing audio, video & populated \\
\hline \multirow[t]{3}{*}{ Browser / Email Data } & Visit site & populated \\
\hline & Bookmark & populated \\
\hline & Email & populated \\
\hline \multirow{2}{*}{ Location data } & Gps cordinates & Populated \\
\hline & Goe-tagged data & populated \\
\hline \multirow{4}{*}{ Calendar, Memos } & Reguler langth & populated \\
\hline & Special character & Populated \\
\hline & Blank entry & populated \\
\hline & Dlete entry & Populated \\
\hline
\end{tabular}

Hasil Pengujian menampilkan laporan umum dari hasil evaluasi pengujian aplikasi WAAT, yang menjelaskan bagaimana aplikasi ini diuji dengan federated testing berdasarkan standar cftt, dengan hasil yang didapatkan sebagai berikut, seperti yang ditampilkan pada tabel 4.

Tabel 4. Hasil Pengujian.

\begin{tabular}{|c|c|c|c|}
\hline \multirow{2}{*}{\multicolumn{2}{|c|}{ Data Objek }} & \multicolumn{2}{|c|}{ Aplikasi } \\
\hline & & \multirow{2}{*}{$\frac{\text { WAAT }}{\times}$} & \multirow{2}{*}{$\begin{array}{c}\text { Federated Testing } \\
\checkmark \checkmark\end{array}$} \\
\hline Contoet/ oddroce ontito & Reguler langth & & \\
\hline contact/ aduress entitas & Blank name & $x$ & $\checkmark$ \\
\hline \multirow{3}{*}{ Call Log } & Group contact & $x$ & $\sqrt{ }$ \\
\hline & Outgoung & $\checkmark$ & $\checkmark$ \\
\hline & Missed & $\checkmark$ & $\checkmark$ \\
\hline \multirow{3}{*}{ Social Media } & Facebook massage & $\checkmark$ & $\checkmark$ \\
\hline & Twitter & $x$ & $\checkmark$ \\
\hline & Instagram & $x$ & $\checkmark$ \\
\hline
\end{tabular}

Muin, et., al [Penerapan CFTT untuk Pengujian Aplikasi Web-Based Android Analysis Tools (WAAT) Dengan Federated Testing] 


\begin{tabular}{|c|c|c|c|}
\hline \multirow{2}{*}{\multicolumn{2}{|c|}{ Data Objek }} & \multicolumn{2}{|c|}{ Aplikasi } \\
\hline & & WAAT & Federated Testing \\
\hline \multirow[t]{2}{*}{ Data File } & Audio & $x$ & $\checkmark$ \\
\hline & Video & $x$ & $\sqrt{ }$ \\
\hline \multirow[b]{2}{*}{ SMS Massage } & Incoming & $\checkmark$ & $\checkmark$ \\
\hline & Outgoing & $\checkmark$ & $\checkmark$ \\
\hline \multirow{2}{*}{ MMS Masage } & Incoming audio, video & $x$ & $\checkmark$ \\
\hline & Outgoing audio, video & $x$ & $\checkmark$ \\
\hline \multirow{3}{*}{ Browser Email Data } & Visit site & $x$ & $\checkmark$ \\
\hline & Bookmark & $x$ & $\checkmark$ \\
\hline & Email & $\checkmark$ & $\checkmark$ \\
\hline \multirow{2}{*}{ Location data } & Gps cordinates & $x$ & $\checkmark$ \\
\hline & Goe-tagged data & $x$ & $\checkmark$ \\
\hline \multirow{4}{*}{ Calendar, Memos } & Reguler langth & $x$ & $\checkmark$ \\
\hline & Special character & $x$ & $\checkmark$ \\
\hline & Blank entry & $x$ & $\checkmark$ \\
\hline & Dlete entry & $x$ & $\checkmark$ \\
\hline Account & Youtube Account & $\checkmark$ & $x$ \\
\hline \multirow{2}{*}{ Data Contact } & Contact phone & $\checkmark$ & $x$ \\
\hline & Countac whatsapp & $\checkmark$ & $x$ \\
\hline \multirow{3}{*}{ Application } & Availible packet & $\checkmark$ & $x$ \\
\hline & Application-install & $\checkmark$ & $x$ \\
\hline & Platform verssion & $\checkmark$ & $\times$ \\
\hline
\end{tabular}

Berdasarkan tabel 6 dapat dilihat bahwa hasil evaluasi pengujian aplikasi WAAT mampu menghasilkan beberapa data sesuai dengan federated testing seperti data call log, social media, sms massage dan data email. Adapun beberapa data yang belum di support aplikasi WAAT disebabkan karena kebutuhan yang digunakan pada saat perancangan sistem aplikasi WAAT tersebut tidak disesuaikan dengan data federated testing sehingga aplikasi tersebut belum mampu menghasilkan data secara menyeluruh.

\section{KESIMPULAN}

Kesimpulan pada penelitian berhasil melakukan pengujian aplikasi WAAT dengan federated testing sesuai standar cftt, dengan hasil yang didapat dari aplikasi web based sebanyak tujuh variabel data yaitu data contact, call log, social media, sms massage, network connected, application, account dan screen lock. Setelah melakukan evaluasi dari hasil kedua aplikasi, didapatkan data yang sesuai dengan laporan federated testing hanya empat variabel data sesuai yaitu call log, social media, sms massage dan data email, adapun beberapa data yang belum di support aplikasi WAAT disebabkan karena kebutuhan yang digunakan pada saat perancangan sistem aplikasi WAAT tersebut tidak disesuaikan dengan data federated testing sehingga aplikasi tersebut belum mampu menghasilkan data secara menyeluruh. 


\section{SARAN}

Diketahui bahwa hasil pengujian aplikasi WAAT belum mampu menghasilkan data secara lengkap sesuai dengan laporan federated testing, hal tersebut disebabkan karena kebutuhan yang digunakan pada saat perancangan sistem tidak sesuai dengan kebutuhan cftt. Sehingga diharapkan kedepannya aplikasi web based bisa dikembangkan yang disesuaikan dengan kebutuhan federated testing sehingga aplikasi web based bisa menghasilkan data yang lebih banyak lagi.

\section{DAFTAR PUSTAKA}

[1] Riadi, I., Fadlil, S., \& Setiawan, M. 2020, Analisis Recovery Bukti Digital Skype Berbasis Smartphone Android Menggunakan Framework NIST.

[2] Yadi, Kunang, 2014, Analisis Forensik pada Platform Android.

[3] Newzoo, 2017, Markets by Smartphone Penetration \& Users, https://newzoo.com/insights/rankings/top-countries-by-ponsel-penetration-and-user.

[4] Riadi, I., Sunardi, S., \& Sahiruddin, S. 2019. Analisis Forensik Recovery pada Smartphone Android Menggunakan Metode National Institute of Justice (NIJ).

[5] Yadi, Kunang, 2014, Analisis Forensik pada Platform Android.

[6] NIST, 2011, Computer Forensics Tools Testing (CFTT) Project Overview in NIST, https://www.nist.gov/itl/ssd/software-quality-group/computer-forensics-tool-testingprogram-cftt.

[7] Horsman, G, 2019, Tool Testing and Reliability Issues In The Field of Digital Forensics. Digital Investigation, 28, 163-175. https://doi.org/10.1016/j.diin.2019.01.009.

[8] Guttman, B., Lyle, J. R., \& Ayers, R. 2014, Ten Years of Computer Forensic Tool Testing. Digital Evidence and Electronic Signature Law Review, 8(0), 139-147. https://doi.org/10.14296/deeslr.v8i0.1963.

[9] Pan, Batten, S. 2009. Digital Forensic Tool Testing Experimental Errors Performance Testing CFReDS Project EESAG.

[10] Roy, S., Wu, Y., \& LaVenia, K. N. 2019. Experience of Incorporating NIST Standards In A Digital Forensics Curricula. 7th International Symposium on Digital Forensics and Security, ISDFS 2019. https://doi.org/10.1109/ISDFS.2019.8757533. 